\title{
PRÁTICAS DESENVOLVIDAS PELOS TÉCNICOS E AUXILIARES DE ENFERMAGEM NA ATENÇÃO BÁSICA
}

\section{Luciana de Oliveira*, Dalvani Marques, Nathalia de Souza Monezi.}

\begin{abstract}
Resumo
Objetivo: Identificar as principais práticas desenvolvidas pelos técnicos e auxiliares de enfermagem que atuam na atenção básica em Campinas/SP. Resultados: Realizadas 150 entrevistas, destacam-se as seguintes atividades realizadas diariamente: Orientações aos usuários, organização do fluxo dentro da unidade, orientação ao público para coleta de exames, verificação da pressão arterial e acolhimento. Conclusão: As auxiliares e técnicas de enfermagem colaboram na execução do trabalho das equipes de saúde, exercendo o trabalho de porta de entrada, pois são as primeiras profissionais a receber as pessoas. Portanto, desenvolvem um amplo de conjunto de atividades na atenção básica, o que demonstra a inserção e a capilaridade do trabalho desses profissionais e sua importância na ESF.
\end{abstract}

Palavras-chave: Enfermagem de Saúde Pública, Prática profissional, Saúde Coletiva.

\section{Introdução}

A Estratégia Saúde da Família (ESF) tem sido fundamental no processo de reorganização da Atenção Básica à Saúde, através de estratégias que qualifiquem, expandem e consolidem a atenção básica, priorizando ações de promoção, prevenção, recuperação e reabilitação da saúde, com ênfase a uma atenção integral que impacte nos determinantes e condicionantes de saúde da população, estimulando a autonomia das pessoas ${ }^{(1,2,3)}$. A equipe de enfermagem é importante para a implantação, ampliação e consolidação da Estratégia de Saúde da Família, experimentando práticas diferenciadas de cuidado ao indivíduo, a família e a comunidade, se aproximando da complexidade da atenção à saúde nesses serviços, trabalhando em equipe multiprofissional, com ênfase na interdisciplinaridade (3). Nesse panorama, esse estudo tem o objetivo de identificar as principais práticas desenvolvidas pelos técnicos e auxiliares de enfermagem que atuam na atenção básica em Campinas/SP.

\section{Resultados e Discussão}

Estudo quantitativo, dados coletados através de entrevistas com um questionário estruturado. A amostra para técnicos e auxiliares de enfermagem da Atenção Básica de Campinas-SP foi aleatória, considerando os cinco distritos de saúde do município. Para estudar as associações entre as variáveis qualitativas foi aplicado o teste Qui-quadrado. Para os casos onde os pressupostos do teste Qui-quadrado não foram atendidos, foi aplicado o teste exato de Fisher. Para todas as análises foi considerado um nível de significância igual a $5 \%$ e o software estatístico SAS versão 9.4 para a realização das mesmas.

Foram realizadas 150 entrevistas e associada as variáveis tempo de serviço com a realização de curativos, acolhimento, aplicação de vacinas, visita domiciliária, registro de produção, atividade de educação permanente e atualização profissional.

Figura 1. Relação entre variáveis

\begin{tabular}{|c|c|c|c|c|c|c|c|c|c|}
\hline \multirow{3}{*}{ Variável } & \multicolumn{8}{|c|}{ Tempo de serviço } & \multirow{3}{*}{ p-valor } \\
\hline & \multicolumn{2}{|c|}{5 anos ou menos } & \multicolumn{2}{|c|}{$6 \mathrm{a} 10$ anos } & \multicolumn{2}{|c|}{11 a 20 anos } & \multicolumn{2}{|c|}{21 anos ou mais } & \\
\hline & $n$ & $\%$ & $n$ & $\%$ & $n$ & $\%$ & $n$ & $\%$ & \\
\hline Se mantém atualizado & & & & & & & & & $0,0328^{*}$ \\
\hline Sim & 47 & 70,15 & 11 & 55,00 & 22 & 51,16 & 17 & 85,00 & \\
\hline Não & 20 & 29,85 & 9 & 45,00 & 21 & 48,84 & 3 & 15,00 & \\
\hline Realização de curativo & & & & & & & & & $0,4518^{*}$ \\
\hline Diariamente & 24 & 35,82 & 6 & 30,00 & 12 & 27,91 & 6 & 30,00 & \\
\hline Semanalmente & 19 & 28,36 & 3 & 15,00 & 16 & 37,21 & 4 & 20,00 & \\
\hline Nunca & 24 & 35,82 & 11 & 55,00 & 15 & 34,88 & 10 & 50,00 & \\
\hline Aplicação de vacinas & & & & & & & & & $0,0226^{*}$ \\
\hline Nunca & 23 & 34,33 & 5 & 25,00 & 27 & 62,79 & 9 & 45,00 & \\
\hline Diariamente & 26 & 38,81 & 8 & 40,00 & 5 & 11,63 & 5 & 25,00 & \\
\hline Eventualmente & 18 & 26,87 & 7 & 35,00 & 11 & 25,58 & 6 & 30,00 & \\
\hline Visita domiciliária & & & & & & & & & $0,3822^{*}$ \\
\hline Nunca & 22 & 32,84 & 7 & 36,84 & 21 & 48,84 & 8 & 40,00 & \\
\hline Diariamente & 21 & 31,34 & 5 & 26,32 & 11 & 25,58 & 9 & 45,00 & \\
\hline Eventualmente & 24 & 35,82 & 7 & 36,84 & 11 & 25,58 & 3 & 15,00 & \\
\hline Registro de produção & & & & & & & & & $0,0414^{* t}$ \\
\hline Nunca & $g$ & 13,43 & 4 & 20,00 & 10 & 23,26 & 10 & 50,00 & \\
\hline Diariamente & 53 & 79,10 & 13 & 65,00 & 29 & 67,44 & $g$ & 45,00 & \\
\hline Eventualmente & 5 & 7,46 & 3 & 15,00 & 4 & 9,30 & 1 & 5,00 & \\
\hline Atividade de educação permanente & & & & & & & & & $0,9039^{*}$ \\
\hline Nunca & 37 & 55,22 & 11 & 55,00 & 27 & 62,79 & $g$ & 45,00 & \\
\hline Eventualmente & 11 & 16,42 & 4 & 20,00 & 7 & 16,28 & 4 & 20,00 & \\
\hline Mensalmente & 19 & 28,36 & 5 & 25,00 & $g$ & 20,93 & 7 & 35,00 & \\
\hline
\end{tabular}

\section{Conclusões}

As auxiliares e técnicas de enfermagem colaboram na execução do trabalho das equipes de saúde, exercendo o trabalho de porta de entrada, pois são as primeiras profissionais a receber as pessoas. Portanto, desenvolvem um amplo de conjunto de atividades na atenção básica, o que demonstra a inserção e a capilaridade do trabalho desses profissionais e sua importância na ESF.

1.Brasil. Ministério da Saúde. Secretaria de Atenção a Saúde. Departamento de Atenção Básica. Política Nacional de Atenção Básica/Ministério da Saúde Secretaria 8 de Atenção à Saúde. Departamento de Atenção Básica. Brasília, 2012.

2. Paim J. O sistema de saúde brasileiro: história, avanços e desafios. The Lancet. P.11- 31, maio. 2011.

3. Marques D, Silva EM. A enfermagem e o programa saúde da família. Rev Bras Enferm. Brasília (DF) 2004, 57(5):545-50. 